\title{
2D QSAR Approach to Develop Newer Analogs as Melatonin Receptor Agonist
}

\section{Supriyo Saha ${ }^{1}$, Mrityunjoy Acharya ${ }^{2}$ and Prinsa $^{3}$}

\author{
${ }^{1}$ Sardar Bhagwan Singh Post Graduate Institute of Biomedical Sciences and Research, \\ Balawala, Dehradun, India \\ ${ }^{2}$ Rastriya Bal Swastha Karyakam, Howrah, West Bengal, India \\ ${ }^{3}$ Ved Life Savers (P) Limited, Dehradun
}

Received: August 05, 2015; Accepted: December 20, 2015; Published (web): February 11, 2016

\begin{abstract}
QSAR analysis was performed using 20 MT1 agonist and 18 MT2 agonist. MODI was 0.6373 in case of MT1 agonist and 0.6299 in case of MT2 agonist. QSAR model for MT1 receptor agonist was pKd $=16.24793(+/$ $0.93539)+1.0924(+/-0.18831) \mathrm{ALogP}-0.11399(+/-0.01383)$ apol +0.59876(+/-0.16599) C2SP3 -10.29435(+/-2.81413) $\mathrm{E} 3 \mathrm{p}$ and for MT2 receptor agonist was $\mathrm{pKd}=6.38692(+/-0.91098)+0.87139(+/-0.20258)$ ALogP $-0.0351(+/-0.00542)$ AMR +3.33079 (+/-0.80377) SpMin6_Bhm +146.76208(+/-28.14492) VE2_Dt with statistical parameter as $\mathrm{Q}^{\wedge} 2: 0.79167, \quad \mathrm{r}^{\wedge} 2 \quad: 0.88878, \quad\left|\mathrm{r} 0^{\wedge} 2-\mathrm{r}^{\prime} 0^{\wedge} 2\right|: 0.04633, \mathrm{k}: 1.03159, \quad\left[\left(\mathrm{r}^{\wedge} 2-\mathrm{r} 0^{\wedge} 2\right) / \mathrm{r}^{\wedge} 2\right]: 0.01013, \quad \mathrm{k}^{\prime}: 0.96695, \quad\left[\left(\mathrm{r}^{\wedge} 2-\right.\right.$ $\left.\left.\mathrm{C}^{\wedge} 2\right) / \mathrm{r}^{\wedge} 2\right]: 0.06226$ and $\mathrm{Q}^{\wedge} 2: 0.81401, \mathrm{r}^{\wedge} 2: 0.97384,\left|\mathrm{r} 0^{\wedge} 2-\mathrm{r}^{\prime} 0^{\wedge} 2\right|: 0.1039, \mathrm{k}: 0.98543,\left[\left(\mathrm{r}^{\wedge} 2-\mathrm{r} 0^{\wedge} 2\right) / \mathrm{r}^{\wedge} 2\right]: 0.08048, \mathrm{k}^{\prime}: 1.01351$, $\left[\left(\mathrm{r}^{\wedge} 2-\mathrm{r}^{\prime} 0^{\wedge} 2\right) / \mathrm{r}^{\wedge} 2\right]: 0.18717$ respectively; comply with the Golbraikh and Tropsha acceptable model criteria. The results from MLR Y Randomization test in case of MT1 agonist was $\mathrm{cRp}^{\wedge} 2: 0.7665$ and MT2 agonist was $\mathrm{cRp}^{\wedge} 2: 0.7284$. Applicability domain were identified by Euclidean and Mahalanobis Distance Method. Finally it was clear that all the predicted data are inside the area of observed data points and also some data are purely overlapped.
\end{abstract}

Key words: Melatonin, MODelability index, golbraikh and tropsha acceptable model, MLR Y randomization, euclidean and mahalanobis distance

\section{INTRODUCTION}

Presently barbiturates, benzodiazepines are being used as sedative hypnotics for the treatment of insomnia. However these drugs have side effects like high abuse potential, cognitive impairment, psychomotor impairment, dependence, tolerance, hangover, rebound insomnia, and so on. ${ }^{1} \mathrm{~A}$ thirst for the discovery of newer hypnotics remains relevant till to date. Circadian rhythm is the term used to describe the physiological and behavioral twenty four hour cycle that most organisms experience. The mammalian biological clock is situated in the suprachiasmatic nucleus ( $\mathrm{SCN})$, which is located in the anterior hypothalamus. ${ }^{2}$ After seeing relation between sleep and release of melatonin there has been a focus on the development of hypnotic agents

Correspondence to: Supriyo Saha

Tel: (+91) 7895424583

Email: supriyo9@gmail.com

Dhaka Univ. J. Pharm. Sci. 15(1): 7-19, 2016 (June) that selectively target melatonin receptors. Melatonin ( $\mathrm{N}$-acetyl-5-methoxytryptamine), the hormone normally secreted from the pineal gland at night, serves as the signal of darkness in the organism and as such plays a pivotal role in the physiological regulation of circadian rhythms, including sleep. ${ }^{3}$ Small number of melatonin receptor agonist like melatonin, ramelteon, tasimelteon, agomelatine are available in the market. Putative melatonin receptors are initially classified into MT1 and MT2, based on the kinetic and pharmacological differences in 2-[ $\left[{ }^{125} \mathrm{I}\right]$ iodomelatonin binding. Melatonin is believed to exert these effects via two specific high affinity guanine nucleotide binding protein ( $\mathrm{G}$ protein coupled receptors) in the SCN, MT1 and MT2. ${ }^{4}$ Exogenous melatonin treatment has a phase shifting effect on circadian rhythms. The influence of an external agent on the biological clock is referred to as the chronobiotic effect. The chronobiotic effect of 
melatonin is due to the presence of MT1 and MT2 receptors in the SCN. MT1 receptors inhibit multiunit activity, while MT2 receptors are responsible for phase shifting responses. It seems likely from in vivo studies that the chronobiotic effect of exogenous melatonin is due to the concerted actions of MT2 resetting the circadian clock and MT1 suppressing neuronal firing at the SCN. Ramelteon has been shown to improve sleep disorders in patients suffering from transient and chronic insomnia without causing significant adverse events. In addition, Ramelteon has a low abuse potential and does not appear to be associated with a withdrawal syndrome or with rebound insomnia. Agomelatine received marketing authorization in the European Union in 2009, for the treatment of depression. In patients with major depression, agomelatine was similarly as effective as paroxetine, sertraline, venlafaxine and fluoxetine, with a lower relapse rate $(23.9 \%)$ compared to the placebo (50.0\%). Tasimelteon has been developed for the treatment of circadian rhythms sleep disorders and approved in the USA in 2014 for the treatment of non-24 h sleepwake disorder in the blind. ${ }^{5}$ Moreover, it has been suggested that melatonin receptor agonists have opportunities to cure various diseases, like Alzheimer disease, bipolar disorder, cancer, hypertension, urinary incontinence, and so on.

In present study we have been develop a QSAR model for the future synthesis of melatonin receptor agonist using melatonin receptor agonist affinity data as biological activity.

\section{MATERIALS AND METHODS}

QSAR model was conducted by using a set of theoretical and constructive descriptors. QSAR Model was constructed by use of MLR Plus Validation Tool. More than 1800 descriptors include Ghose-Cripen Log Ko/w, Ghose-Crippen molar refractivity, Sum of the atomic polarizabilities (including implicit hydrogens), Wildman- Crippen $\log \mathrm{P}$ and MR, Wildman-Crippen MR, Eccentric Connectivity Index: topological descriptor combining distance and adjacency information, $\mathrm{H}$ Bond
Acceptor Count Number of hydrogen bond acceptors, McGowan characteristic volume, Wiener Polarity Number, Kappa shape indices, Electrotopochemical atom were calculated by PADEL and ToMoCoMD software. All the explanations of relevant descriptors were enlisted in (Table 1). A descriptor represents a quantitative property depends on the molecular structure. Theoretical descriptors were advantageous due to its free from uncertainty of experimental measurement and can be calculated for compounds before synthesis. Theoretical descriptors were employed in this QSAR study to model as melatonin (MT1 \& MT2) receptor agonist.

Table 1. List of relevant descriptor with explanation.

\begin{tabular}{ll}
\hline $\begin{array}{l}\text { Abbreviation } \\
\text { descriptors }\end{array}$ & Explanation of descriptors \\
\hline AlogP & Ghose-Crippen LogKow \\
SpMin3_Bhv & $\begin{array}{l}\text { Burden modified eigenvalues } \\
\text { Total number of Nitrogen Atoms }\end{array}$ \\
ETA_Beta_ns & $\begin{array}{l}\text { A measure of electron-richness of the } \\
\text { molecule }\end{array}$ \\
Crippen MR & Crippen's molar refractivity \\
McGowan volume & McGowan characteristic volume \\
VABC & Van der Waals volume calculated \\
nRing & No of ring \\
nRotb & No of rotatable bonds \\
Phia Kappa & flexibility index \\
Bac & Balaban centric index \\
AlogP & Ghose-Crippen LogKow \\
Crippen LogP & Crippen's LogP \\
XLogP & XLogP \\
AMR & Molar refractivity \\
TopoPSA & Topological polar surface area \\
Wpol & Weiner polarity number \\
MW & Molecular weight \\
ETA & Electro topochemical descriptor \\
\hline
\end{tabular}

Dataset and descriptor calculation. Dataset of 20 melatonin receptor MT1 agonist and 18 MT2 agonist were extracted. ${ }^{6-20}$ All the molecules SMILE format were transferred into .mol format by ACDLABS and structures were optimized. 2D and 3D descriptors were calculated using PADEL descriptor $^{21}$ and ToMoCoMD ${ }^{22}$ software.

MO Delability index calculation. MODelability index $^{23}$ was a way to estimate for every compound present in a dataset with the smallest Euclidean distance in the entire descriptor space belongs to 
same or different activity class. The number of nearest neighbor pairs that were not activity cliff was counted for each class of compounds using proper threshold value.

Descriptor pretreatment. Inter correlated descriptor was cut off using $\mathrm{V}-\mathrm{WSP}^{24}$ as variance cut off 0.0001 and correlation coefficient value 0.99 .

Dataset division. Dataset of 20 molecules as MT1 agonist was divided into 14 molecules in training and 6 molecules in Test set using Kennard Stone method and Dataset of 18 molecules as MT2 agonist was divided into 12 molecules in training and 6 molecules in test set using Kennard Stone method.

Suitable descriptor selection. Suitable descriptor selection was performed using stepwise MLR as $F$ values 3.9 to 4.0. Then best subset was selected using 4 descriptor combination and $\mathrm{r} 2$ cut off value 0.6 .

The chemometric tool. The development of QSAR equation was implemented two methods (1) Stepwise regression (2) multiple linear regressions with factor analysis as pre processing factor analysis for variable selection (FA-MLR).

Stepwise regression. Multi step linear equation, a multistep equation was built by step by step. The basic procedure involved: (i) Identifying an initial model (ii) Repeating the previous step by altering descriptor or variable combination to achieve better $F$ and $\mathrm{r} 2$ value. (iii) Calibrate the equation by justify the values in between observed and predicted values. The stepwise MLR was performed using statistical software SPSS and it was judged by parameters as explained variance $\left(\mathrm{r}^{2} \mathrm{a}\right)$, correlation coefficient $(\mathrm{r})$, standard error of estimate (s) and variance ratio (F) at a specified degree of freedom (DF). All accepted MLR equation had regression level significant at 95 and $99 \%$ levels. The generated QSAR equation was validated by leave one out or LOO method using Minitab software and different parameters like cross validation $\mathrm{r} 2$ (q2), standard deviation based on press $\left(\mathrm{S}_{\text {PRESS }}\right)$ and standard deviation of error of prediction $(\mathrm{SDEP}){ }^{25}$

FA-MLR. In this case a final statistical tool was used to develop a QSAR relation, factor analysis as a data pre processing step to identify the important factor to identify the important variables contributing the response variable by avoiding co linear value. The data matrix is first standardized and correlation matrix and subsequently reduced correlation matrix. An eigen value problem is then solved and the factor pattern can be obtained from the corresponding eigen vectors. The main objectives are to display multidimensional data in space of lower dimensionality with minimum loss of information (explaining $>95 \%$ of variance of data matrix) and to extract the basic features behind the data with ultimate goal of interpretation. ${ }^{26}$

QSAR equation development. MLR plus valid software was used to developed QSAR equation, where $\mathrm{pKd}$ value was used as biological effect. ${ }^{27,28}$

QSAR equation validation. Golbraikh and Tropsha acceptable model criteria' $\mathrm{s}^{29-31}$ to validate a QSAR equation:

1. $\mathrm{Q}^{\wedge} 2$ value is passed (Threshold value $\mathrm{Q}^{\wedge} 2>0.5$ ).

2. $r^{\wedge} 2$ value is passed (Threshold value $r^{\wedge} 2>0.6$ ).

3. $\left|\mathrm{r}^{\wedge} 2-\mathrm{r}^{\prime} 0^{\wedge} 2\right|$ value is passed (Threshold value $\left.\left|\mathrm{r} 0 \wedge 2-\mathrm{r}^{\prime} 0^{\wedge} 2\right|<0.3\right)$.

QSAR equation cross validation. The model was cross validated using Leave-One-Out (LOO) process. ${ }^{32}$ Applicability domain of the developed QSAR equation was checked based on the response and chemical structure space in which the QSAR model makes predictions with a given reliability. Euclidean distance ${ }^{33}$ and Mahalanobis ${ }^{34}$ distance method. The distance of a test compound to its nearest neighbor in the training set is compared to the predefined applicability domain threshold.

MLR Y randomization test. In this test, random MLR models were generated by randomly shuffling the dependent variable while keeping the independent variables as it is. The new QSAR models were expected to have significantly high R2 and Q2 values for several trials, which confirm that the developed QSAR models were robust. Another parameter, $\mathrm{cRp} 2$ was also calculated which should be more than 0.5 for passing this test. ${ }^{35}$

$$
\text { cRp2 }=\mathrm{R} *(\mathrm{R} 2-(\text { Average } \mathrm{Rr}) 2) 1 / 2 \quad \text { where, }
$$
Average $R r=$ average ' $R$ ' of random models. 


\section{RESULTS AND DISCUSSION}

The total dataset of 20 MTI receptor agonist and 18 MT2 receptor agonist were subdivided into training and test set along with chemical structure and pKd (affinity towards MT1 \& MT2 receptor) as biological effect was diagrammatized in (Tables 2 and 3). The outcome from MODelability index was
0.6373 with threshold value 0.65 and total actives/toxic $(\mathrm{H}): 17.0000$ total less actives/less toxic (L): 3.0000 in case of MT1 agonist and 0.6299 with threshold value 0.65 and total actives/toxic $(\mathrm{H})$ : 11.0000 total less actives/less toxic (L): 7.0000 in case of MT2 agonist and detail of MODelability Index was diagrammatized in (Table 4). In case of

Table 2. Detail list of training set molecule with affinity towards MT1 and MT2 receptor.

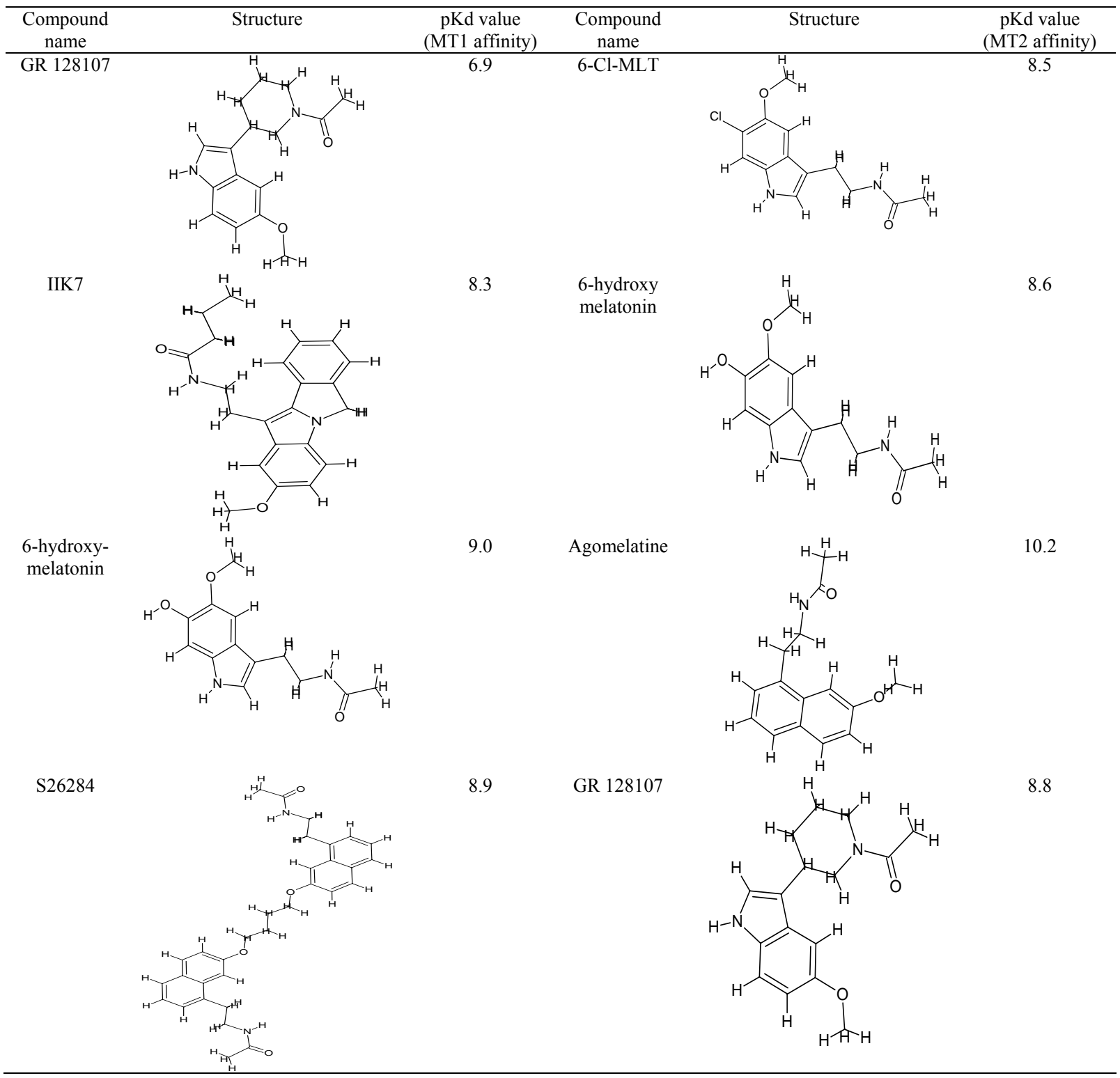




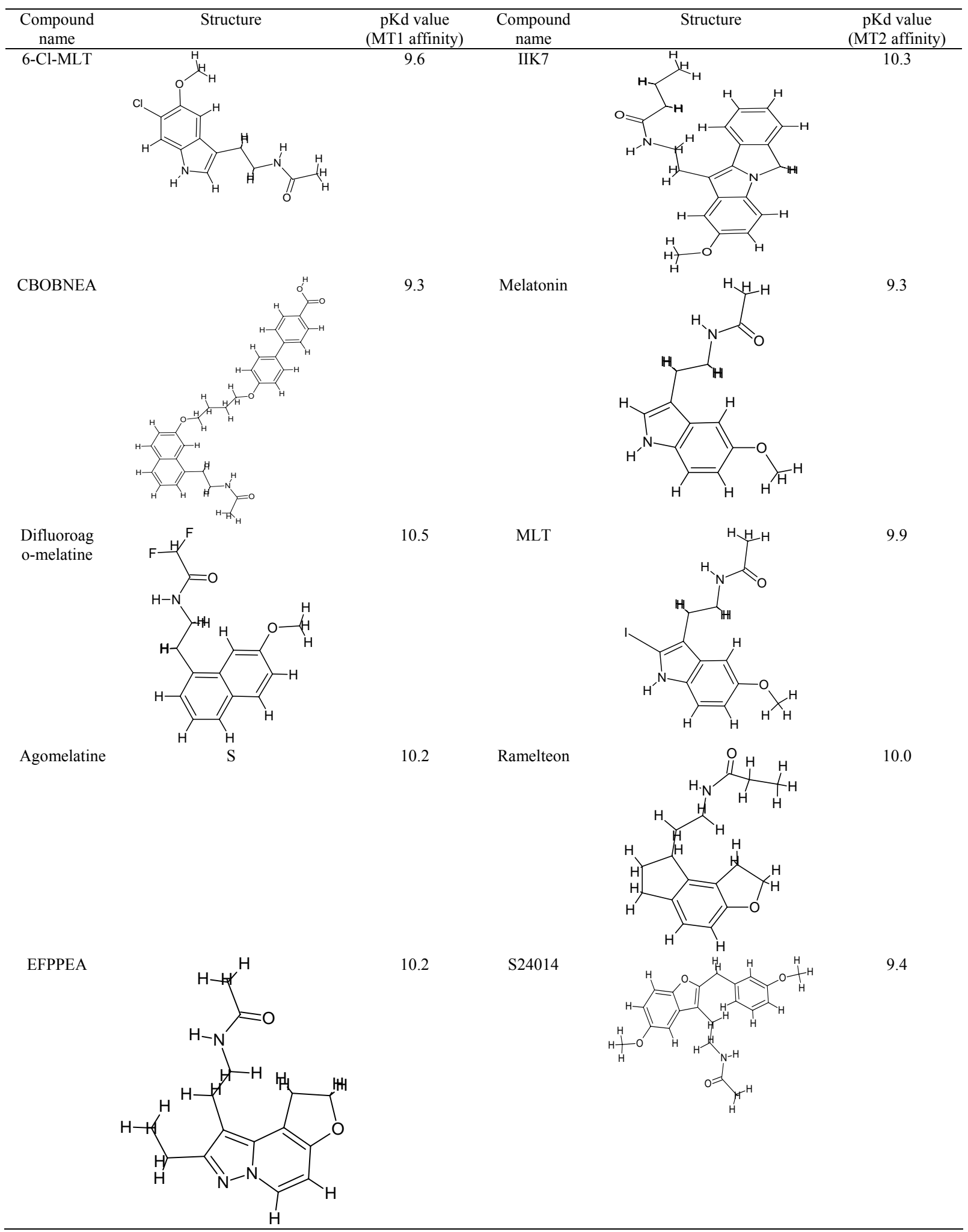




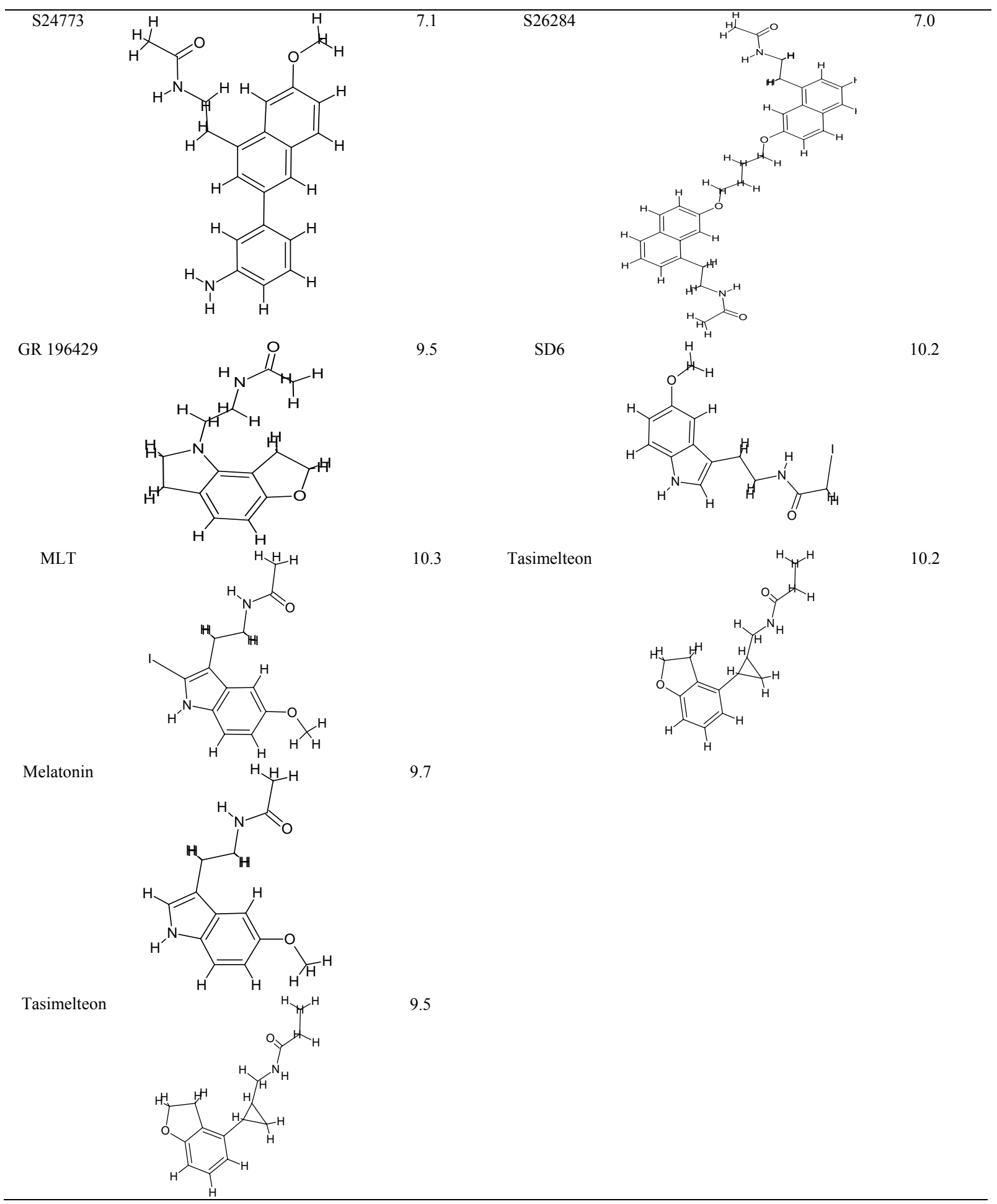

MT1 receptor agonist, the statistically suitable QSAR model was $\mathrm{pKd}=16.24793(+/-0.93539)+1.0924(+/-$ 0.18831) $\quad \mathrm{ALog} \mathrm{P} \quad-0.11399(+/-0.01383) \quad$ apol $+0.59876(+/-0.16599)$ C2SP3 -10.29435(+/-2.81413)
E3p with statistical information as SEE :0.37938, $\mathrm{r}^{\wedge} 2$ :0.91973, $\mathrm{r}^{\wedge} 2$ adjusted :0.88405,F :25.77921 (DF :4, 9) and Leave-One-Out (LOO) result was Q2 :0.79167,PRESS :3.3618,SDEP :0.49003 and in case 
Table 3. Detail list of test set molecule with affinity towards MT1 and MT2 receptor.

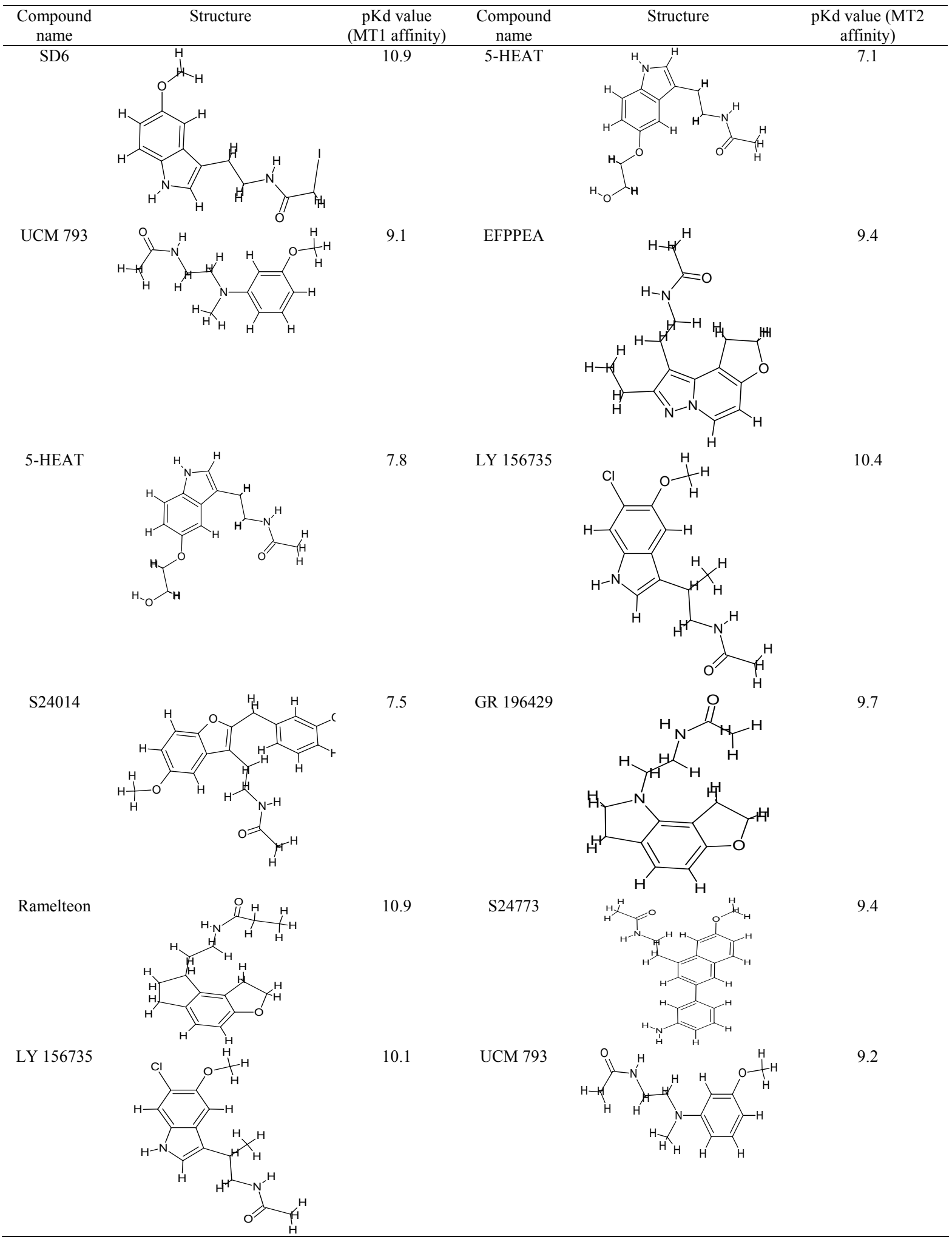


Table 4. MODelability Index of total dataset for MT1 and MT2 receptor agonist.

\begin{tabular}{ll}
\hline MT1 & MT2 \\
\hline True positives: 16.0000 & True positives: 6.0000 \\
True negatives: 1.0000 & True negatives: 5.0000 \\
Total actives/toxic (H): 17.0000 & Total actives/toxic (H): 11.0000 \\
Total less_actives/less toxic (L): 3.0000 & Total less_actives/lesstoxic (L): 7.0000 \\
MODelability Index (MODI): 0.6373 & MODelability Index (MODI): 0.6299 \\
(Threshold value: MODI:0.65) & (Threshold value: MODI:0.65) \\
\hline
\end{tabular}

Table 5. Internal validation parameters and LOO result of QSAR model for MT1 and MT2 agonist.

\begin{tabular}{ll}
\hline \multicolumn{1}{c}{ MT1 } & \multicolumn{1}{c}{ MT2 } \\
\hline Internal validation parameters: & Internal validation parameters: \\
SEE $: 0.38624, \mathrm{r}^{\wedge} 2: 0.90291, \mathrm{r}^{\wedge} 2$ adjusted $: 0.85976$, & SEE $: 0.33652, \mathrm{r}^{\wedge}: 0.92765, \mathrm{r}^{\wedge} 2$ adjusted $: 0.8863$, \\
$\mathrm{F}: 20.92422(\mathrm{DF}: 4,9)$ & $\mathrm{F}: 22.43744(\mathrm{DF}: 4,7$. \\
& \\
& Leave-One-Out (LOO) result: \\
Leave-One-Out $(\mathrm{LOO})$ result: & Q2 $: 0.81401$ \\
$\mathrm{Q} 2: 0.75169$, PRESS $: 3.43374$, & PRESS $: 2.0378$ \\
SDEP $: 0.49524$ & SDEP $: 0.41209$ \\
\end{tabular}

Table 6. Golbraikh and Tropsha acceptable model criteria's of QSAR Model for MT1 and MT2 receptor agonist.

\begin{tabular}{ll}
\hline MT1 & \multicolumn{1}{c}{ MT2 } \\
\hline $\mathrm{Q}^{\wedge} 2: 0.75169:$ Passed (Threshold value $\left.\mathrm{Q}^{\wedge} 2>0.5\right)$ & $\mathrm{Q}^{\wedge} 2: 0.81401$ Passed (Threshold value $\left.\mathrm{Q}^{\wedge} 2>0.5\right)$ \\
$\mathrm{r}^{\wedge} 2: 0.81812:$ Passed (Threshold value $\left.\mathrm{r}^{\wedge} 2>0.6\right)$ & $\mathrm{r}^{\wedge} 2: 0.97384$ Passed (Threshold value $\left.\mathrm{r}^{\wedge} 2>0.6\right)$ \\
$\left|\mathrm{r} 0^{\wedge} 2-\mathrm{r}^{\prime} 0^{\wedge} 2\right|: 0.21411:$ Passed (Threshold value & {$\left[\left(\mathrm{r}^{\wedge} 2-\mathrm{r} 0^{\wedge} 2\right) / \mathrm{r}^{\wedge} 2\right]: 0.08048$ : Passed (Threshold value $\mid \mathrm{r} 0^{\wedge} 2-$} \\
$\left.\left|\mathrm{r} 0^{\wedge} 2-\mathrm{r}^{\prime} 0^{\wedge} 2\right|<0.3\right)$ & $\left.\mathrm{r}^{\prime} 0^{\wedge} 2 \mid<0.3\right)$ \\
$\mathrm{k}: 1.01023 \quad \mathrm{k}^{\prime}: 0.98397$ & $\mathrm{~K}: 0.98543, \mathrm{k}^{\prime}: 1.01351$ \\
$0.85<\mathrm{k}<1.15 ; 0.85<\mathrm{k}^{\prime}<1.15$ & $0.85<\mathrm{k}<1.15 ; 0.85<\mathrm{k}^{\prime}<1.15$ \\
$\left.\left.\left(\mathrm{r}^{\wedge} 2-\mathrm{r} 0^{\wedge} 2\right) / \mathrm{r}^{\wedge} 2\right]: 0.09894 ;\left(\mathrm{r}^{\wedge} 2-\mathrm{r}^{\prime} 0^{\wedge} 2\right) / \mathrm{r}^{\wedge} 2\right]: 0.60511$ & {$\left[\left(\mathrm{r}^{\wedge} 2-\mathrm{r} 0^{\wedge} 2\right) / \mathrm{r}^{\wedge} 2\right]: 0.08048 ;\left[\left(\mathrm{r}^{\wedge} 2-\mathrm{r} 0^{\wedge} 2\right) / \mathrm{r}^{\wedge} 2\right]: 0.08048$} \\
Threshold value: & Threshold value: \\
$\left(\left(\mathrm{r}^{\wedge} 2-\mathrm{r}^{\wedge} 2\right) / \mathrm{r}^{\wedge} 2\right)<0.1$ & $\left(\left(\mathrm{r}^{\wedge} 2-\mathrm{r}^{\wedge} 2\right) / \mathrm{r}^{\wedge} 2\right)<0.1$ \\
$\left.\left(\mathrm{r}^{\wedge} 2-\mathrm{r}^{\prime} 0^{\wedge} 2\right) / \mathrm{r}^{\wedge} 2\right)<0.1$ & $\left.\left(\mathrm{r}^{\wedge} 2-\mathrm{r}^{\prime} 0^{\wedge} 2\right) / \mathrm{r}^{\wedge} 2\right)<0.1$ \\
\hline & \\
\hline
\end{tabular}

of MT2 receptor agonist most valid QSAR model was $\mathrm{pKd}=6.38692(+/-0.91098)+0.87139(+/-$ 0.20258) ALogP $-0.0351(+/-0.00542) \quad$ AMR $+3.33079(+/-0.80377)$ SpMin6_Bhm +146.76208(+/28.14492) VE2_Dt with statistical information as SEE :0.33652, $\mathrm{r}^{\wedge} 2$ :0.92765, $\mathrm{r}^{\wedge} 2$ adjusted :0.8863,F :22.43744 (DF :4, 7) and Leave-One-Out (LOO) result was Q2 :0.81401,PRESS :2.0378,SDEP $: 0.41209$; all the information were reported in (Table 5). The outcomes from Golbraikh and Tropsha acceptable model criteria in case of MT1 agonist was $\mathrm{Q}^{\wedge} 2: 0.79167, \quad \mathrm{r}^{\wedge} 2 \quad: 0.88878, \quad\left|\mathrm{r}^{\wedge} 2-\mathrm{r}^{\prime} 0^{\wedge} 2\right|: 0.04633$, $\mathrm{k}: 1.03159,\left[\left(\mathrm{r}^{\wedge} 2-\mathrm{r}^{\wedge} 2\right) / \mathrm{r}^{\wedge} 2\right]: 0.01013, \mathrm{k}^{\prime}: 0.96695,\left[\left(\mathrm{r}^{\wedge} 2-\right.\right.$ $\left.\left.' 0^{\wedge} 2\right) / \mathrm{r}^{\wedge} 2\right]: 0.06226$ and in case of MT2 receptor agonist was $\quad \mathrm{Q}^{\wedge} 2: 0.81401, \mathrm{r}^{\wedge} 2: 0.97384, \mid \mathrm{r} 0^{\wedge} 2$ $\mathrm{r}^{\prime} 0^{\wedge} 2 \mid: 0.1039, \mathrm{k}: 0.98543,\left[\left(\mathrm{r}^{\wedge} 2-\mathrm{r} 0^{\wedge} 2\right) / \mathrm{r}^{\wedge} 2\right]: 0.08048$, $\mathrm{k}^{\prime}: 1.01351,\left[\left(\mathrm{r}^{\wedge} 2-\mathrm{r}^{\prime} 0^{\wedge} 2\right) / \mathrm{r}^{\wedge} 2\right]: 0.18717$ and all data were put in (Table 6). The results from MLR Y Randomization test in case of MT1 receptor agonist was Average r: 0.5299; Average $\mathrm{r}^{\wedge} 2$ : 0.2997, $\mathrm{cRp}^{\wedge} 2$ : 0.7665 and incase of MT2 receptor agonist was Average r: 0.596281; Average $\mathrm{r}^{\wedge} 2$ : 0.3705, $\mathrm{cRp}^{\wedge} 2$ : 0.7284.after generation of 10 randomized model and cited in (Table 7). The outcomes from applicability domain analysis by Euclidean and Mahalanobis distance methods are quite satisfactory within the normal distribution range and reported at (Tables 89). As per the Euclidean Distance method; in case of MT1 receptor agonist in the Training set, GR128107 and melaotnin molecule were with highest and lowest Euclidean distance score and in case of test set SD6 and UCM-793 were responsive for highest score and lowest Euclidean score respectively; and in case of MT2 receptor agonist in the training set; S26284 and 
Tasimelteon scored highest and lowest Euclidean distance and in case of test test; Lys15735 \& 5HEAT had lowest Euclidean distance. In case of Mahalanobis distance of MT1 receptor agonist, compound CBOBNEA with highest Mahalanobis distance of 3.12079 and melatonin with lowest Mahalanobis distance of 1.07321 among the training set compounds and compound SD6 with highest distance score of 2.04131 and ramelteon with 2.04121 lowest distance score among the test compounds as well as in case of MT2 receptor agonist compound S26284 and melatonin with highest and lowest mahalanobis distance respectively present inside the Training set and compound 5HEAT and EFPPEA with highest and lowest mahalanobis distance respectively present inside the

Table 7. MLR Y Randomization parameter of QSAR model for MT1 and MT2 receptor agonist.

\begin{tabular}{|c|c|c|c|c|c|c|c|}
\hline \multicolumn{3}{|c|}{ MT1 } & \multicolumn{5}{|c|}{ MT2 } \\
\hline Model & $\mathrm{R}$ & $\mathrm{R}^{\wedge} 2$ & $\mathrm{Q}^{\wedge} 2$ & Model & $\mathrm{R}$ & $\mathrm{R}^{\wedge} 2$ & $\mathrm{Q}^{\wedge} 2$ \\
\hline Original & 0.950215 & 0.902909 & 0.751692 & Original & 0.963145 & 0.927648 & 0.814013 \\
\hline Random 1 & 0.487802 & 0.23795 & -0.6698 & Random 1 & 0.502735 & 0.252742 & -2.65212 \\
\hline Random 2 & 0.454858 & 0.206896 & -1.78859 & Random 2 & 0.551771 & 0.304451 & -1.92808 \\
\hline Random 3 & 0.690764 & 0.477154 & -1.28509 & Random 3 & 0.847809 & 0.718781 & -0.07028 \\
\hline Random 4 & 0.50136 & 0.251362 & -1.08514 & Random 4 & 0.649433 & 0.421763 & -1.10612 \\
\hline Random 5 & 0.831797 & 0.691885 & -0.37734 & Random 5 & 0.483084 & 0.23337 & -6.76295 \\
\hline Random 6 & 0.746983 & 0.557983 & -0.98014 & Random 6 & 0.675838 & 0.456757 & -4.07822 \\
\hline Random 7 & 0.431915 & 0.186551 & -2.44783 & Random 7 & 0.618921 & 0.383064 & -1.92944 \\
\hline Random 8 & 0.328784 & 0.108099 & -0.55611 & Random 8 & 0.488362 & 0.238498 & -2.2368 \\
\hline Random 9 & 0.439431 & 0.193099 & -0.87155 & Random 9 & 0.714532 & 0.510555 & -7.33119 \\
\hline Random 10 & 0.330369 & 0.109143 & -0.77793 & Random 10 & 0.430322 & 0.185177 & -2.85435 \\
\hline \multicolumn{4}{|c|}{ Random models parameters: } & \multicolumn{4}{|c|}{ Random models parameters: } \\
\hline \multicolumn{4}{|c|}{ Average r: 0.5299 ; Average $\mathrm{r}^{\wedge} 2: 0.2997$} & \multirow{2}{*}{\multicolumn{4}{|c|}{$\begin{array}{l}\text { Average r: } 0.596281 \text {; Average } \mathrm{r}^{\wedge} 2: 0.3705 \\
\mathrm{cRp}^{\wedge} 2: 0.7284 .\end{array}$}} \\
\hline $\mathrm{cRp}^{\wedge} 2: 0.76$ & & & & & & & \\
\hline
\end{tabular}

Table 8. Applicability domain analysis by Euclidean distance of QSAR model for MT1 and MT2 receptor agonist.

\begin{tabular}{|c|c|c|c|c|c|c|c|c|}
\hline \multirow{16}{*}{$\begin{array}{l}\text { For training } \\
\text { set }\end{array}$} & & \multicolumn{3}{|c|}{ MT1 } & \multicolumn{4}{|c|}{ MT2 } \\
\hline & $\begin{array}{c}\text { Comp } \\
\text { No }\end{array}$ & $\begin{array}{l}\text { Euclidean } \\
\text { Distance }\end{array}$ & $\begin{array}{c}\text { Mean } \\
\text { Distance }\end{array}$ & $\begin{array}{c}\text { Norm } \\
\text { mean } \\
\text { Distance }\end{array}$ & $\begin{array}{l}\text { Comp } \\
\text { No }\end{array}$ & $\begin{array}{l}\text { Euclidean } \\
\text { Distance }\end{array}$ & $\begin{array}{c}\text { Mean } \\
\text { Distance }\end{array}$ & $\begin{array}{c}\text { Norm } \\
\text { mean } \\
\text { Distance }\end{array}$ \\
\hline & 1 & 18.3742 & 1.4134 & 0.006461 & 1 & 186.906 & 16.9915 & 0.016965 \\
\hline & 2 & 29.3515 & 2.25781 & 0.387112 & 2 & 205.036 & 18.6396 & 0.033326 \\
\hline & 3 & 18.5399 & 1.42614 & 0.012205 & 3 & 257.69 & 23.4264 & 0.080841 \\
\hline & 4 & 40.9301 & 3.14847 & 0.78861 & 4 & 170.522 & 15.502 & 0.00218 \\
\hline & 5 & 20.9634 & 1.61257 & 0.096242 & 5 & 168.782 & 15.3439 & 0.00061 \\
\hline & 6 & 18.6995 & 1.43842 & 0.01774 & 6 & 224.598 & 20.418 & 0.050978 \\
\hline & 7 & 47.0262 & 3.6174 & 1 & 7 & 177.66 & 16.1509 & 0.008621 \\
\hline & 8 & 18.477 & 1.42131 & 0.010026 & 8 & 190.315 & 17.3014 & 0.020042 \\
\hline & 9 & 26.4992 & 2.0384 & 0.288202 & 9 & 168.287 & 15.2988 & 0.000163 \\
\hline & 10 & 18.1879 & 1.39907 & 0 & 10 & 1276.25 & 116.023 & 1 \\
\hline & 11 & 20.3548 & 1.56575 & 0.07514 & 11 & 172.601 & 15.691 & 0.004056 \\
\hline & 12 & 20.1491 & 1.54993 & 0.068008 & 12 & 168.106 & 15.2824 & 0 \\
\hline & 13 & 27.5724 & 2.12096 & 0.325419 & & & & \\
\hline & 14 & 24.9762 & 1.92125 & 0.235392 & & & & \\
\hline \multirow[t]{6}{*}{ For test set } & 1 & 11.0276 & 2.20551 & 0.449819 & 1 & 119.526 & 23.9053 & 0 \\
\hline & 2 & 14.0678 & 2.81356 & 1 & 2 & 122.804 & 24.5608 & 0.007491 \\
\hline & 3 & 10.8855 & 2.1771 & 0.424111 & 3 & 127.894 & 25.5789 & 0.019126 \\
\hline & 4 & 11.3875 & 2.27749 & 0.514951 & 4 & 557.044 & 111.409 & 1 \\
\hline & 5 & 8.87877 & 1.77575 & 0.060962 & 5 & 119.742 & 23.9483 & 0.000492 \\
\hline & 6 & 8.5419 & 1.70838 & 0 & 6 & 121.972 & 24.3945 & 0.00559 \\
\hline
\end{tabular}


Table 9. Applicability domain analysis by Mahalanobis distance of QSAR model for MT1 and MT2 receptor agonist.

\begin{tabular}{|c|c|c|c|c|}
\hline \multirow{3}{*}{ For training set } & \multicolumn{2}{|c|}{ MT1 } & \multicolumn{2}{|l|}{ MT2 } \\
\hline & Comp no. & Maha distance & Comp no. & Maha distance \\
\hline & 1 & 2.09035 & 1 & 3.00369 \\
\hline & 2 & 2.39464 & 2 & 2.26994 \\
\hline & 3 & 1.12236 & 3 & 1.12924 \\
\hline & 4 & 3.12079 & 4 & 1.92141 \\
\hline & 5 & 2.71822 & 5 & 1.97132 \\
\hline & 6 & 1.74566 & 6 & 0.916055 \\
\hline & 7 & 2.74391 & 7 & 2.35256 \\
\hline & 8 & 1.54564 & 8 & 1.57018 \\
\hline & 9 & 2.3087 & 9 & 2.33515 \\
\hline & 10 & 1.07321 & 10 & 3.13976 \\
\hline & 11 & 1.2857 & 11 & 1.75533 \\
\hline & 12 & 1.69115 & 12 & 2.17734 \\
\hline & 13 & 2.57867 & & \\
\hline \multirow[t]{8}{*}{ For test set } & 14 & 2.42869 & & \\
\hline & Comp no. & Maha distance & Comp no. & Maha distance \\
\hline & & 2.04126 & 1 & 2.0413 \\
\hline & 2 & 2.04123 & 2 & 2.04078 \\
\hline & 3 & 2.04121 & 3 & 2.04121 \\
\hline & 4 & 2.04122 & 4 & 2.04121 \\
\hline & 5 & 2.04131 & 5 & 2.04126 \\
\hline & 6 & 2.04126 & 6 & 2.04093 \\
\hline
\end{tabular}

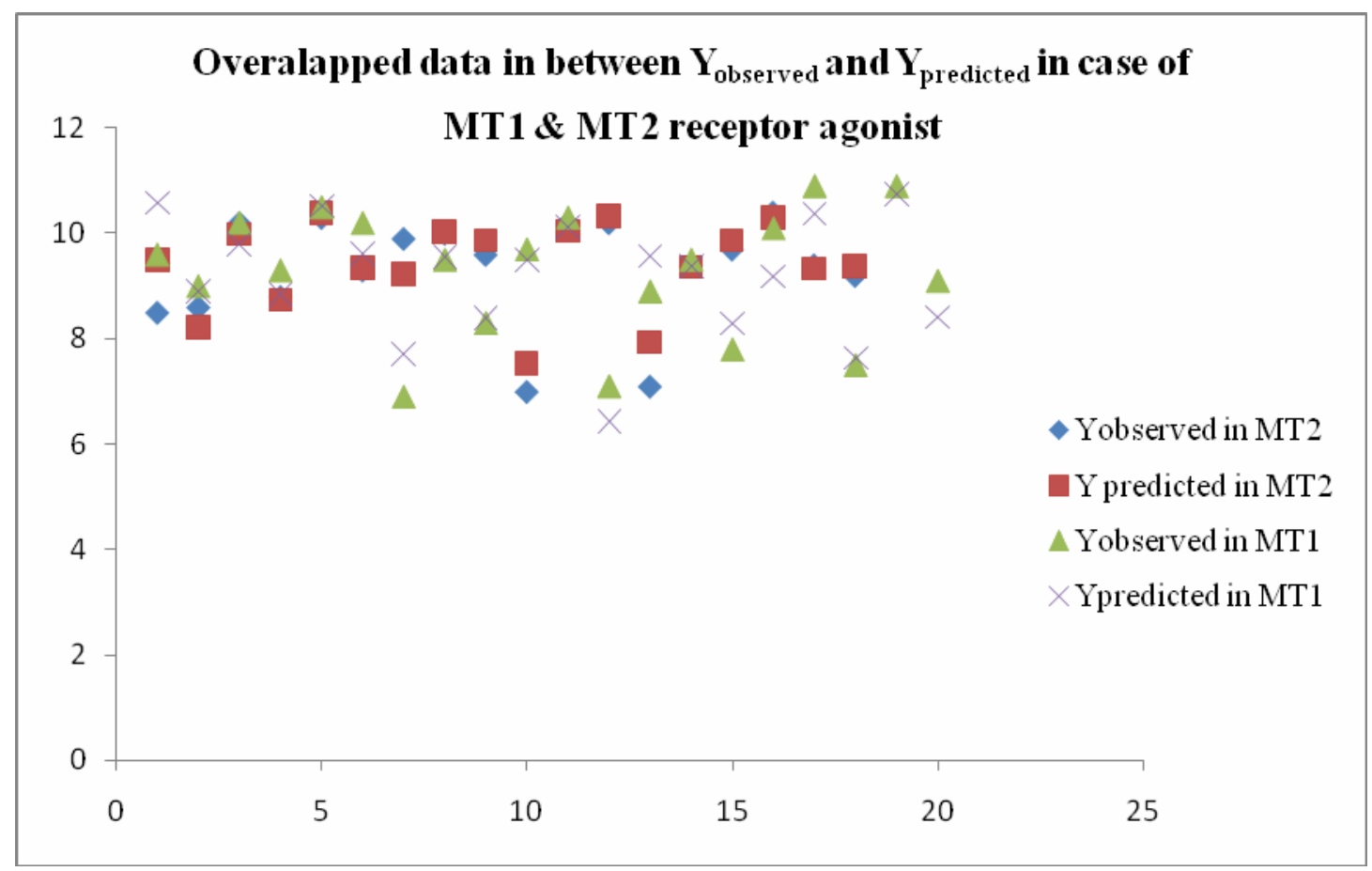

Figure 1. Overlapped data in between $\mathrm{Y}_{\text {Observed }} \mathrm{pKd}$ and $\mathrm{Y}_{\text {Predicted }}$ in case of MT1 and MT2 receptor agonist.

test set. Finally the data overlapping was done in between observed and predicted data and the results are reported at (Figure 1). In case of MT1 receptor agonist MODelability Index of the total dataset was 0.6373 with the threshold value 0.65 and in case of MT2 receptor agonist was 0.6299 which reflects that prediction capacity of the developed QSAR model will have statistical parameters just above the acceptable limit r2:0.6 and q2 0.5. The developed QSAR model for MT1 receptor agonist was $\mathrm{pKd}=$ 16.24793(+/-0.93539) +1.0924(+/-0.18831) ALogP $0.11399(+/-0.01383) \quad$ apol $\quad+0.59876(+/-0.16599)$ 
C2SP3 -10.29435(+/-2.81413) E3p which suggests that $\mathrm{A} \log \mathrm{P}$ as Ghose-Crippen LogKow, apol as Sum of the atomic polarizabilities (including implicit hydrogens), C2SP3 as Singly bound carbon bound to two other carbons and E3p as 3rd component accessibility directional WHIM index / weighted by relative polarizabilities are the essential parameters to optimize to improvise the biological activity and in case of MT2 receptor agonist, pKd $=6.38692(+/-$ $0.91098)+0.87139(+/-0.20258)$ ALogP $-0.0351(+/-$ 0.00542) AMR +3.33079(+/-0.80377) SpMin6_Bhm $+146.76208(+/-28.14492)$ VE2_Dt which reflects that $\mathrm{A} \log \mathrm{P}$ as Ghose-Crippen $\operatorname{LogKow}$, AMR as Molar refractivity, SpMin6_Bhm and VE2_Dt as Average coefficient sum of the last eigenvector from detour matrix. In case of MT1 receptor agonist Ghose-Crippen LogKow and C2SP3 presence modify the activity profile towards positive direction and in case of MT2 receptor agonist; Ghose-Crippen LogKow and VE2_Dt give positive response towards biological activity. Among the two QSAR model one parameter as $\mathrm{ALog} \mathrm{P}$ is common, so we have to emphasize on the partition coefficient value along with molar refractivity, relative polarizability and 2D matrix descriptors. ${ }^{36,37}$ The statistical information was SEE: 0.37938, $\mathrm{r}^{\wedge} 2$ : 0.91973, $\mathrm{r}^{\wedge} 2$ adjusted: 0.88405, F: 25.77921 (DF: 4, 9) and SEE: 0.33652, $\mathrm{r}^{\wedge} 2$ : 0.92765, $\mathrm{r}^{\wedge} 2$ adjusted: 0.8863, F: 22.43744 (DF: 4, 7) in case of MT1 and MT2 receptor agonist QSAR model reflects that all the parameters are in the acceptable range. In case of MT1 receptor agonist QSAR model: the difference between the $r 2$ and $r 2$ adj value is 0.03523 which is less than 0.3 indicates that the number of descriptors involved in the QSAR model is acceptable and $\mathrm{F}$ test ratio value 25.77921 also reflects the greater predictability of the QSAR model. In the LOO result the difference between $\mathrm{r} 2$ and q2 (without scaling) is 0.07149 with accessible limit 0.3 which reflect the good predictability of the QSAR model. The $\mathrm{rm}^{\wedge} 2$ (test) value for external validation is 0.80442 which must be greater than 0.5 as a good external predictability parameter. For a QSAR model can be considered acceptable if the values of $\mathrm{r} 2 \mathrm{~m}$ (overall) and $\mathrm{r} 2 \mathrm{p}$ are equal to or above 0.5 (or at least near 0.5); in this developed QSAR model $\mathrm{r} 2 \mathrm{~m}$ is 0.80442 and $\mathrm{r} 2 \mathrm{p}$ is 0.83739 . The results from Golbraikh and Tropsha acceptable model criteria's are $\mathrm{Q}^{\wedge} 2: 0.79167, \mathrm{r}^{\wedge} 2 \quad: 0.88878, \quad \mid \mathrm{r} 0^{\wedge} 2$ $\mathrm{r}^{\prime} 0^{\wedge} 2 \mid: 0.04633, \quad \mathrm{k}: 1.03159,\left[\left(\mathrm{r}^{\wedge} 2-\mathrm{r} 0^{\wedge} 2\right) / \mathrm{r}^{\wedge} 2\right]: 0.01013$, $\mathrm{k}^{\prime}: 0.96695,\left[\left(\mathrm{r}^{\wedge} 2-^{\prime} 0^{\wedge} 2\right) / \mathrm{r}^{\wedge} 2\right]: 0.06226$ and in case of MT2 receptor agonist was $\mathrm{Q}^{\wedge} 2: 0.81401, \mathrm{r}^{\wedge} 2$ : $0.97384,\left|\mathrm{r} 0 \wedge 2-\mathrm{r}^{\prime} 0^{\wedge} 2\right|: 0.1039, \mathrm{k}: 0.98543,\left[\left(\mathrm{r}^{\wedge} 2-\right.\right.$ $\left.\left.\mathrm{r} 0^{\wedge} 2\right) / \mathrm{r}^{\wedge} 2\right]: 0.08048, \quad \mathrm{k}^{\prime}: 1.01351,\left[\left(\mathrm{r}^{\wedge} 2-\mathrm{r}^{\prime} 0^{\wedge} 2\right) / \mathrm{r}^{\wedge} 2\right]:$ 0.18717 which also shown that the predictability of the model is quite high and the Y Randomization test result also shown that $\mathrm{cRp}^{\wedge} 2$ : 0.7665 which must be greater than 0.5 for good predictability. In case of MT2 receptor agonist QSAR model: the difference between the $r 2$ and $r 2$ adj value is 0.04135 which is less than 0.3 indicates that the number of descriptors involved in the QSAR model is acceptable and F test ratio value 22.43744 also reflects the greater predictability of the QSAR model. In the LOO result the difference between $\mathrm{r} 2$ and $\mathrm{q} 2$ (without scaling) is 0.01228 with accessible limit 0.3 which reflect the good predictability of the QSAR model. The $\mathrm{rm}^{\wedge} 2$ (test) value for external validation is 0.70121 which must be greater than 0.5 as a good external predictability parameter. For a QSAR model can be considered acceptable if the values of $\mathrm{r} 2 \mathrm{~m}$ (overall) and $\mathrm{r} 2 \mathrm{p}$ are equal to or above 0.5 (or at least near 0.5 ); in this developed QSAR model $\mathrm{r} 2 \mathrm{~m}$ is 0.70121 and $r 2 p$ is $0.88118 .^{31}$ The results from Golbraikh and Tropsha acceptable model criteria's are $\mathrm{Q}^{\wedge} 2: 0.79167$, $\mathrm{r}^{\wedge} 2$ :0.88878, $\left|\mathrm{r} 0^{\wedge} 2-\mathrm{r}^{\prime} 0^{\wedge} 2\right|: 0.04633, \mathrm{k}: 1.03159,\left[\left(\mathrm{r}^{\wedge} 2-\right.\right.$ $\left.\mathrm{r} 0 \wedge 2) / \mathrm{r}^{\wedge} 2\right]: 0.01013, \quad \mathrm{k}^{\prime}: 0.96695,\left[\left(\mathrm{r}^{\wedge} 2-^{\prime} 0^{\wedge} 2\right) / \mathrm{r}^{\wedge} 2\right]$ : 0.06226 and in case of MT2 receptor agonist was $\mathrm{Q}^{\wedge} 2: 0.81401, \mathrm{r}^{\wedge} 2: 0.97384,\left|\mathrm{r} 0^{\wedge} 2-\mathrm{r}^{\prime} 0^{\wedge} 2\right|: 0.1039, \mathrm{k}:$ $0.98543,\left[\left(\mathrm{r}^{\wedge} 2-\mathrm{r} 0^{\wedge} 2\right) / \mathrm{r}^{\wedge} 2\right]: 0.08048, \quad \mathrm{k}^{\prime}: 1.01351,\left[\left(\mathrm{r}^{\wedge} 2-\right.\right.$ $\left.\left.\mathrm{r}^{\prime} 0^{\wedge} 2\right) / \mathrm{r}^{\wedge} 2\right]: 0.18717$ which also shown that the predictability of the model is quite high and the $\mathrm{Y}$ Randomization test result also shown that $\mathrm{cRp}^{\wedge} 2$ : 0.7284 which must be greater than 0.5 for good predictability. As per the data from Applicability Domain analysis not a single molecule is outside the domain. Finally as per the overlapping data, it is quite clear that all the predicted data are inside the area of observed data points and also some data are purely overlapped. 


\section{ACKNOWLEDGEMENT}

One of the authors is highly acknowledged towards Prof. Veerma Ram, Head of the Department, SBSPGI for his unconditional support and well beings.

\section{REFERENCES}

1. David, C.L. and Kathy, L.F. 2004. The clinical basis of medical toxicology. Sed. Hypn. 74, 1060-1071.

2. Masaomi, M. 2009. Pharmacology of Ramelteon- a Selective MT1/MT2 Receptor Agonist: A novel therapeutic drug for sleep disorders. CNS. Neurosci. Therapeu. 15, 32-51.

3. Moshe, L. and Anat, F.M. 2014. Therapeutic effects of melatonin receptor agonists on sleep and comorbid disorders. Int. J. Mol. Sci. 15, 15924-15950.

4. QueraSalva, M.A. and Hartley, S. 2012. Mood Disorders, Circadian Rhythms, Melatonin and Melatonin Agonists. $J$. Central. Nervous. System. Dis. 4, 15-26

5. Nermien, E.W. and Richard, H. 2015. Circadian pattern of melatonin MT1 and MT2 receptor localization in the rat suprachiasmatic nucleus. J. Circadian. Rhythms. 1, 1-7.

6. Legros, C., Matthey, U., Grelak, T., Pedragona, M.S., Hassler, W., Yous, S., Thomas, E., Suzenet, F., Folleas, B. and Lefoulon, F. 2013. New radioligands for describing the molecular pharmacology of MT1 and MT2 melatonin receptors. Int. J. Mol. Sci. 14 , 8948-8962.

7. Audinot, V., Mailliet, F., Lahaye, B.C., Bonnaud, A., Le Gall, A., Amosse, C., Dromaint, S., Rodriguez, M., Nagel, N., Galizzi, J.P., Malpaux, B., Guillaumet, G., Lesieur, D. Lefoulon, F., Renard, P., Delagrange, P. and Boutin, J.A. 2003. New selective ligands of human cloned melatonin MT1 and MT2 receptors. Naunyn. Schmiedebergs. Arch. Pharmacol. 367, 553-561.

8. Dubocovich, M.L., Masana, M.I., Iacob, S. and Sauri, D.M. 1997. Melatonin receptor antagonists that differentiate between the human $\mathrm{Mel}_{1 \mathrm{a}}$ and $\mathrm{Mel}_{\mathrm{lb}}$ recombinant subtypes are used to assess the pharmacological profile of the rabbit retina $\mathrm{ML}_{1}$ presynaptic heteroreceptor. Naunyn. Schmiedebergs. Arch. Pharmacol. 355, 365-375.

9. Browning, C., Beresford, I., Fraser, N. and Giles, H. 2000. Pharmacological characterization of human recombinant melatonin MT (1) and MT (2) receptors. Brazil. J. Pharmacol. 129, 877-886.

10. Kato, K., Hirai, K., Nishiyama, K., Uchikawa, O., Fukatsu, K., Ohkawa, S., Kawamata, Y., Hinuma, S. and Miyamoto, M. 2005. Neurochemical properties of ramelteon (TAK-375), a selective MT1/MT2 receptor agonist. Neuropharmacol. 48, 301-310.
11. Rawashdeh, O., Hudson, R. L., Stepien, I. and Dubocovich, M.L. 2011. Circadian periods of sensitivity for ramelteon on the onset of running-wheel activity and the peak of suprachiasmatic nucleus neuronal firing rhythms in $\mathrm{C} 3 \mathrm{H} / \mathrm{HeN}$ mice. Chronobiol. Int. 28, 31-38.

12. Dubocovich, M.L. 1985. Characterization of a retinal melatonin receptor. J. Pharmacol. Exp. Ther. 234, 395-401.

13. Beresford, I.J., Browning, C., Starkey, S.J., Brown, J., Foord, S.M., Coughlan, J., North, P.C., Dubocovich, M.L. and Hagan, R.M. 1998. GR196429: a nonindolic agonist at highaffinity melatonin receptors. J. Pharmacol. Exp. Ther. 285, 1239-1245.

14. Morellato, L., Lefas, L.G.M., Langlois, M., Caignard, D.H., Renard, P., Delagrange, P. and Mathe, A.M. 2013. Synthesis of new N-(arylcyclopropyl)acetamides and $\mathrm{N}$-(arylvinyl) acetamides as conformationally-restricted ligands for melatonin receptors. Bioorg. Med. Chem. Lett. 23, 430-434.

15. Ettaoussi, M., Sabaouni, A., Rami, M., Boutin, J.A., Delagrange, P., Renard, P., Spedding, M., Caignard, D.H., Berthelot, P. and Yous, S. 2012. Design, synthesis and pharmacological evaluation of new series of naphthalenic analogues as melatoninergic (MT1/MT2) and serotoninergic 5-HT2C dual ligands (I). Eur. J. Med. Chem. 49, 310-323.

16. Koike, T., Takai, T., Hoashi, Y., Nakayama, M., Kosugi, Y., Nakashima, M., Yoshikubo, S., Hirai, K. and Uchikawa, O. 2011. Synthesis of a novel series of tricyclic dihydrofuran derivatives: discovery of 8,9-dihydrofuro[3,2-c] pyrazolo [1,5-a]pyridines as melatonin receptor (MT1/MT2) ligands. $J$. Med. Chem. 54, 4207-4218.

17. Mulchahey, J.J., Goldwater, D.R. and Zemlan, F.P. 2004. A single blind, placebo controlled, across groups dose escalation study of the safety, tolerability, pharmacokinetics and pharmacodynamics of the melatonin analog beta-methyl-6chloromelatonin. Life Sci. 75, 1843-1856.

18. Mesangeau, C., Peres, B., Descamps, F.C., Chavatte, P., Audinot, V., Coumailleau, S., Boutin, J.A., Delagrange, P., Bennejean, C. and Renard, P. 2010. Design, synthesis and pharmacological evaluation of novel naphthalenic derivatives as selective MT (1) melatoninergic ligands. Bioorg. Med. Chem. 18, 3426-3436.

19. Rivara, S., Lodola, A., Mor, M., Bedini, A., Spadoni, G., Lucini, V., Pannacci, M., Fraschini, F., Scaglione, F. and Sanchez, R.O. 2007. N-(substituted-anilinoethyl) amides: design, synthesis, and pharmacological characterization of a new class of melatonin receptor ligands. J. Med. Chem. 50, 6618-6626. 
20. Nonno, R., Lucini, V., Spadoni, G., Pannacci, M., Croce, A., Esposti, D., Balsamini, C., Tarzia, G., Fraschini, F. and Stankov, B.M. 2000. A new melatonin receptor ligand with mt1-agonist and MT2-antagonist properties. J. Pineal. Res. 29, 234-240.

21. Yap, C.W. 2011. PaDEL-descriptor: an open source software to calculate molecular descriptors and fingerprints. J. Comput. Chem. 32, 1466-1474.

22. Garcia, J., Marrero-Ponce, C.R., Acevedo, M.Y., Barigye, L., Valdes, S.J. and Contrerastorres, J.R. 2014. QuBiLSMIDAS: A parallel free-software for molecular descriptors computation based on multi-linear algebraic maps. J. Comput. Chem. 35, 1395-1409.

23. Golbraikh, A., Muratov, E., Fourches, D. and Tropsha, A. 2014. Data set modelability by QSAR. J. Chem. Inf. Model. 54, 1-4.

24. Ballabio, D., Consonni, V., Claeys- Bruno, M., Sergent, M. and Todeschini, R. 2014. A novel variable reduction method adapted from space-filling designs. Chemometrics. Intelligent. Laboratory. Systems. 136, 147-154.

25. Roy, K. and Kar, S. 2014. The rm2 metrics and regression through origin approach: reliable and useful validation tools for predictive QSAR models (Commentary on 'Is regression through origin useful in external validation of QSAR models?'). Eur. J. Pharm. Sci. 62, 111-114.

26. Roy, K. and Mitra, I. 2011. On various metrics used for validation of predictive QSAR models with applications in virtual screening and focused library design. Comb. Chem. High. Throughput. Screen. 14, 450-474.

27. Roy, K., Das, R.N. and Paul, L.A. 2014. Quantitative structure-activity relationship for toxicity of ionic liquids to Daphnia magna Aromaticity vs. lipophilicity. Chemosphere. 112, 120-127.

28. Garg, R. and Carr, J.S. 2014. Predicting the bioconcentration factor of highly hydrophobic organic chemicals. Food. Chem. Toxicol. 69, 252-259.
29. Dearden, J.C. and Hewitt, M. 2010. QSAR modeling of bioconcentration factor using hydrophobicity,hydrogen bonding and topological descriptor. SAR. QSAR. Environ. Res. 21, 671-680.

30. Dimitrov, S.D., Dimitrova, N.C., Walker, J.D., Veith, G.D. and Mekenyan, O.G. 2002. Predicting bioconcentration factors of highly hydrophobic chemicals. Effects of molecular size. Pure. Appl. Chem. 74, 1823-1830.

31. Ravichandran, V., Rajak, H., Jain, A., Sivadasan, S., Varghese, C.P. and Agrawal, R.K. 2011. Validation of QSAR models - strategies and importance. Int. J. Drug. Design. Discovery. 3, 511-19.

32. Krstajic, D., Buturovic, L.J., Leahy, D.E. and Thomas, S. 2014. Cross-validation pitfalls when selecting and assessing regression and classification models. J. Cheminform. 6, 1-15.

33. Zhang, S., Golbraikh, A., Oloff, S., Kohn, H. and Tropsha, A. 2006. J. Chem. Inf. Model. 46, 1984-1995.

34. Jaworska, J., Nikolova-Jeliazkova, N. and Aldenberg, T. 2005. QSAR applicability domain estimation by projection of the training set in descriptor space: A review. ATLA. 33, 445459.

35. Rucker, C., Rucker, G. and Meringer, M. 2007. YRandomization and its variants in QSPR/QSAR. J. Chem. Inf. Model. 47, 2345-2357.

36. Humberto, F.F., Tania, F.B. and Marcelo, S.C. 2013. 2D chemometric studies of a series of azole derivatives active against fluconazole-resistantCryptococcus gattii. J. Braz. Chem. Soc. 24, 962-972.

37. Kim, J.H. 2012. Is it possible to predict the ADI of pesticides using the QSAR approach? J. Environ. Health Sci. 38, 550560 . 